\title{
Laparoscopically Assisted Appendicectomy in Adults: A comparative analysis
}

\author{
Misauno M.A., Isichei M.W., ALE A.F. \\ Department of Surgery, Jos University Teaching Hospital, Jos Nigeria
}

\begin{abstract}
Background; Laparoscopic appendicectomy (LA) has always generated controversy due to its expensive and time consuming nature. Open appendicectomy $(O A)$ on the other hand is cheaper and faster to perform but lacks the advantage of visualising the rest of the peritoneal cavity for associated pathologies. Laparoscopically assisted appendicectomy (LAA) in comparison combines the benefits of the other methods at a cheaper rate than the laparoscopic appendicectomy but is performed mainly in children. This study was aimed at evaluating the feasibility of LAA in adults compared to LA and OA. Methodology-This was a combined prospective and retrospective evaluation of patients that underwent appendicectomy using three different methods. Results The prospective arm of the study consisted of a total of 64 patients, 28 of whom had laparoscopic appendicectomy while 36 had laparoscopically assisted appendicectomy. The retrospective arm included 40 patients that had open appendicectomy. The costs of the procedures were $\$ 315(O A), \$ 630(L A A)$ and $\$ 1260$ (LA). The mean operating time for the different methods were 30, 33 and 60 minutes for OA, LAA and LA respectively while the duration of hospital admission were 24hours each for OA and LAA but 48 hours for LA. Associated intra-abdominal pathologies were found in 13 patients (20.3\%) that had LAA and LA while none was documented for OA. Conclusion Laparoscopically assisted appendicectomy (LAA) in adults can be done at a significantly reduced cost and shorter operating time when compared to Laparoscopic appendicectomy (LA), and has the ability to detect other intraabdominal pathologies as opposed to open appendicectomy.
\end{abstract}

Keywords: Adult laparoscopic assisted appendicectomy, cheaper, faster, detects other pathologies

Submitted Date 27 June 2013

Accepted Date: 02 July 2013

\section{Introduction}

Despite the numerous advantages attributable to laparoscopic surgery, Laparoscopic appendicectomy continues to generate considerable debate among surgeons when compared to open appendicectomy.(1-4)this debate has revolved around the relatively longer operating time(5-6), the high cost of the procedure(7) and the multiple trocar points required in standard laparoscopic appendicectomy which arguably approximates to the length of the incision in open appendicectomy. Despite this controversy, the opportunity for surgeons to visualise the rest of the peritoneal cavity during laparoscopic appendicectomy is too important to be ignored(8) and is perhaps the most important reason why surgeons find laparoscopic appendicectomy appealing despite its time consuming and expensive nature.(9-10)

Open appendicectomy on the other hand is easier to perform, less expensive and has a shorter operating time even though the patients stay longer in hospital and the surgeon does not have the opportunity to visualise the rest of the peritoneal cavity.

Appreciating this dilemma, laparoscopic surgeons have always been in search of the best way to remove the appendix with minimal cost, shortest possible operating time

while maintaining the full benefits of the laparoscopic approach. This search gave birth to laparoscopically assisted appendicectomy which is widely practised in children with little documentation of this procedure in adults (11-12).

This was aimed at evaluating the feasibility of laparoscopically assisted appendectomy (LAA) as compared to the conventional open appendicectomy (OA) and the laparoscopic appendicectomy (LA) in adults.

\section{Patients and Methods}

This was a combined prospective and retrospective evaluation of patients that underwent appendicectomy using three different methods. Consecutive patients diagnosed with appendicitis and slated for appendicectomy were initially done laparoscopically but when we ran short of endoloops and clips, we switched over to LAA. These patients that had LA and LAA were prospectively analysed and then compared with a retrospective cohort of patients that had OA. 
Consecutive patients with clinical diagnosis of appendicitis presenting to these centres during the study period formed the basis of this study while those with generalised peritonitis from appendiceal rupture and those that decline consent were excluded from the study.

Anaesthesia techniques and patient positioning were the same for both LA and LAA

For Laparoscopic appendicectomy (LA), the following steps were observed:

1. An open access laparoscopic technique was used with a $10 \mathrm{~mm}$ camera port in the umbilicus; a Verre's needle was not used.

2. A $5 \mathrm{~mm}$ port was then inserted under direct vision at the suprapubic region and another $10 \mathrm{~mm}$ port was inserted at the left iliac fossa also under direct vision and served as the main working port.

3. The appendix was picked up with a grasper through the suprapubic port, dissected out, the vascular pedicle clipped and transacted, two endoloops were then applied at the base of the appendix and the appendix was transected between the endoloops and inserted into a retrieval bag and delivered through the umbilical port.

4. Port site wounds were then closed with vicryl 0 suture.

The steps involved in laparoscopically assisted appendicectomy include:

1. An open access laparoscopic technique was used with a $10 \mathrm{~mm}$ camera port in the umbilicus.

2. A second $10 \mathrm{~mm}$ port was inserted in the RIF through which the appendix was grasped, peritoneal cavity desufflated, both appendix and port were delivered ("port exteriorization") on to the exterior and appendicectomy effected like in the open technique. (Fig. 1)

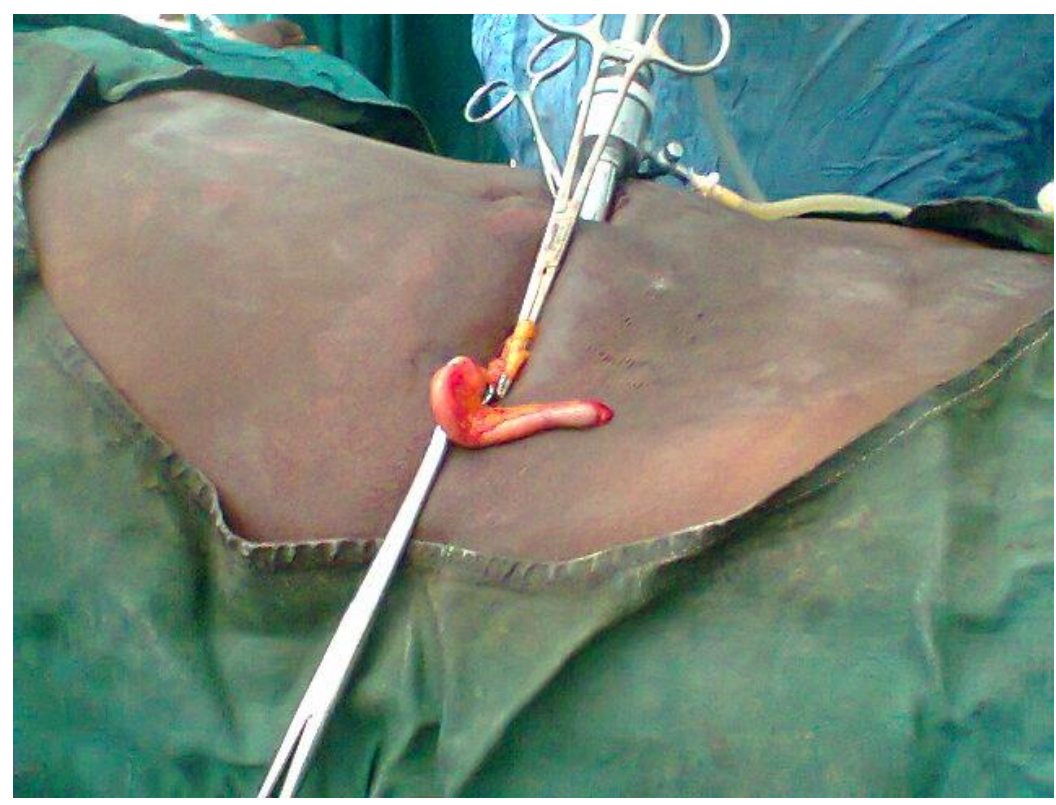

Fig. 1 showing the delivered appendix in the right iliac fossa with the meso appendix clamped and divided.

3. The appendiceal stump was then dropped and the peritoneal cavity inspected a second time before port site closure with vicryl 0 sutures.

4. Consumables like Endoloops and clips were not necessary.

5. A third port may be required in the left iliac fossa or suprapubic region to aid mobilisation of a difficult appendix.

Data obtained included age, sex and BMI, Cost of procedure, durations of procedure and hospital stay, coexisting intra-abdominal pathology and complications.

For the retrospective arm of the study, case notes of consecutive patients that had elective open appendicectomy during the same period were retrospectively analysed and compared with those of LA and LAA Data obtained was analysed for simple means and percentages using Epi Info statistical software version 3.5.1

\section{Results}

A total of 36 laparoscopically assisted appendectomies were performed during the study period in 4 males and 32 females $(\mathrm{M}: \mathrm{F}=1: 8)$. The mean age of the study population was $27.7 \pm 9.7$ years and the mean operating time was 33 minutes with a range of 30-45 minutes. (Table1) 
Table of Operating time, Length of hospital stay and cost for LAA, OA, LA

LAA(Laparoscopy assisted appendicectomy)

OA(Open

\begin{tabular}{|l|l|l|l|}
\hline Surgery & $\begin{array}{l}\text { Mean Operating } \\
\text { time(min) }\end{array}$ & $\begin{array}{l}\text { Mean duration of } \\
\text { hospital stay(hrs) }\end{array}$ & Cost(US Dollar) \\
\hline OA & 30 & 48 & 315 \\
\hline LAA & 33 & 24 & 630 \\
\hline LA & 60 & 24 & 1260 \\
\hline
\end{tabular}

appendicectomy)

LA (Laparoscopic appendicectomy)

Associated intra-abdominal pathologies were found in 10 patients $(27.8 \%)$ with pelvic adhesions accounting for seven, ovarian cyst 3 .

There were two complications in this study; 1 being subcutaneous emphysema and the other $(2.8 \%)$ patient had umbilical port site infection. The average cost of this procedure was one hundred thousand naira (\$630USD) and patients were all discharged within 24 hours of the procedure.

On the other hand, laparoscopic appendicectomy was performed on 28 patients; four of whom were males and 24 females $(\mathrm{M}: \mathrm{F}=1: 6)$. The mean age of this cohort was $29.3 \pm 10.1$ years and the mean operating time was 60 minutes with a range of 40-130 minutes.

Three patients had pelvic adhesions as associated intra-abdominal pathologies. One patient had port site infection as complication. The mean cost of this procedure was two hundred thousand naira (\$1260 USD) and all patients were also discharged home within $24 \mathrm{hrs}$.

40 patients that had open appendicectomy among whom are 4 males and 36 females (M: $F=1: 9)$. Their mean age was $28.2 \pm 10.3 \mathrm{yrs}$. The mean operating time was 30 minutes with a range of 20 to 55 minutes. There were no documentation of associated pathologies and only 1 patient had wound infection as a complication. The cost of the procedure was fifty thousand naira (\$315USD) and all patients were discharged after 48 hours. There were no mortalities in all the series.

\section{Discussion}

The main finding in this study was the wide difference in the cost of the procedures, with LA costing twice LAA and four times OA. This cost difference is due to expensive laparoscopic surgery consumables like endoloops and endoclips which are not required in LAA and OA and is in agreement with the findings of other researchers (13-14).

The operating time for LA ranged from 40-130 minutes. The longer operating times were incurred during the learning curve and progressively got shorter as the researchers gained more experience. The Mean operating time for LA is about twice that of the other methods. This could be attributable to the time spent in insertion of the numerous ports, application of clips and endoloops when compared to the other methods in consonance with Berger et al's report.(15)

Up to $20 \%$ of patients that had LA and LAA were noticed to have associated intra abdominal pathologies while in OA, there was no documentation of intraabdominal pathology. This suggests that we may be missing associated intra abdominal pathologies in one out of every five patients we offer open appendicectomy. In an earlier study from the same institution, a negative appendicectomy rate of $20 \%$ was reported by Ogbonna et al following open appendicectomy and corroborated by other studies $(5,16)$.

There is no significant difference in the infection rates in all three methods. Although hospital stay in OA was longer, it was still cheaper suggesting that the exorbitant cost of LA may not be from hospital stay but from the consumables.

\section{Conclusion}

It can be concluded that LAA in adults can be done at a significantly reduced cost and shorter operating time when compared to LA, and has the ability to detect other intraabdominal pathologies as opposed to open appendicectomy.

\section{References}

11] Gauderer MW. An individualized approach to appendectomy in children based on anatomico-laparoscopic findings. Am Surg. 2007 Aug;73(8):814-7.

]2] Casanelli JM, Keli E, N'Dri J, Aboua G, Keita M, Meneas G, et al. [Evaluation of a four-year experience with laparoscopic surgery in Abidjan, Ivory Coast]. Med Trop (Mars). 2007 Oct;67(5):481-4.

13] Roviaro GC, Vergani C, Varoli F, Francese M, Caminiti R, Maciocco M. Videolaparoscopic appendectomy: the current outlook. Surg Endosc. 2006 Oct;20(10):1526-30. 
]4] Kargar S, Mirshamsi MH, Zare M, Arefanian S, Shadman Yazdi E, Aref A. Laparoscopic versus open appendectomy; which method to choose? A prospective randomized comparison. Acta Med Iran. 2011;49(6):352-6.

15] Scott-Conner CE, Hall TJ, Anglin BL, Muakkassa FF. Laparoscopic appendectomy. Initial experience in a teaching program. Ann Surg. 1992 Jun;215(6):660-7; discussion 7-8.

16] Baraza R. Re: laparoscopic appendicectomy. East Afr Med J. 2004 Mar;81(3):164-5; author reply 6.

]7] Shalaby R, Arnos A, Desoky A, Samaha AH. Laparoscopic appendectomy in children: evaluation of different techniques. Surg Laparosc Endosc Percutan Tech. 2001 Feb;11(1):22-7.

]8] Patel SC, Jumba GF, Akmal S. Laparoscopic appendicectomy at the Aga Khan Hospital, Nairobi. East Afr Med J. 2003 Sep;80(9):447-51.

19] Harbrecht BG, Franklin GA, Miller FB, Smith JW, Richardson JD. Acute appendicitis--not just for the young. Am J Surg. 2011 Sep;202(3):286-90.

110] McGrath B, Buckius MT, Grim R, Bell T, Ahuja V. Economics of appendicitis: cost trend analysis of laparoscopic versus open appendectomy from 1998 to 2008. J Surg Res. 2011 Dec;171(2):e161-8.

]11] Koudelka J, Janecek L, Kuliacek P, Kralova M. [Laparoscopy-assisted appendectomy in children]. Rozhl Chir. 1996 Oct;75(10):482-5.

]12] El-Gohary MA, El-Marsafawy M. Port-exteriorization appendectomy (PEA): a preliminary report. Pediatr Surg Int. 2001;17(1):3941.

113] Visnjic S. Transumbilical laparoscopically assisted appendectomy in children: high-tech low-budget surgery. Surg Endosc. 2008 Jul;22(7):1667-71.

]14] Stanfill AB, Matilsky DK, Kalvakuri K, Pearl RH, Wallace LJ, Vegunta RK. Transumbilical laparoscopically assisted appendectomy: an alternative minimally invasive technique in pediatric patients. J Laparoendosc Adv Surg Tech A. 2010 Dec;20(10):873-6.

115] Beger HG, Schwarz A, Bergmann U. Progress in gastrointestinal tract surgery: the impact of gastrointestinal endoscopy. Surg Endosc. 2003 Feb;17(2):342-50.

]16] Ogbonna BC, Obekpa PO, Momoh JT, Ige JT, Ihezue CH. Another look at acute appendicitis in tropical Africa: and the value of laparoscopy in diagnosis. Trop Doct. 1993 Apr;23(2):82-4. 